\title{
Quantitative Genetic Analysis of Three Important Nutritive Traits in the Fruit of Avocado
}

\author{
Carlos Calderón-Vázquez¹, Mary L. Durbin, Vanessa E.T.M. Ashworth², Livia Tommasini, \\ Kapua K.T. Meyer, and Michael T. Clegg ${ }^{3}$ \\ Department of Ecology and Evolutionary Biology, University of California, 498 Steinhaus Hall, \\ Irvine, CA 92697
}

\begin{abstract}
AdDitional INDEX wORDS. Persea americana, molecular markers, vitamins, tocopherol, sitosterol, breeding
Abstract. Avocado (Persea americana) is a subtropical tree prized for its large and nutritious fruit. Although native to Mesoamerica, avocado is now grown in tropical and subtropical regions around the world, and consumer demand for avocado continues to grow at a considerable rate. Despite the appeal of avocado, its genetic improvement has been slow owing to substantial land and labor requirements combined with the fact that young trees do not produce fruit for several years and a pollination system that makes it difficult to produce genetic crosses. Molecular markers promise to accelerate the rate of breeding progress, especially for simple traits of high heritability. One of the distinguishing features of the avocado fruit is the presence of a number of compounds that have been linked to human health. As a prelude to the use of molecular markers for the improvement of nutritional traits, this article reports estimates of the heritability of carotenoids, $\beta$-sitosterol, and $\alpha$-tocopherol content (the most biologically active form of vitamin E) in ripe avocado fruit. Each of these three compounds has been linked to beneficial health outcomes, and each is shown to have a sufficiently high heritability to predict successful marker-assisted selection.
\end{abstract}

Avocado is a diploid $(2 \mathrm{n}=24)$, outcrossing tree with a genome size of $883 \mathrm{Mb}$ (Arumuganathan and Earle, 1991). Widely grown throughout tropical and subtropical regions of the world, it is valued for its nutritious fruit (Bergh, 1992, Ding et al., 2007). Avocado is native to Mexico and Central America where it was domesticated an estimated 2900 to 8400 years ago (Smith, 1966), although more recent sources (Galindo-Tovar et al., 2008) narrow the range to $\approx 4000$ to 6500 years ago. Domestication took place at least three times, yielding the three distinct races of cultivated avocado that are used today (see Ashworth et al., 2011). This history of separate domestications results in a wide base of genetic variation (Chen et al., 2008, 2009) and accounts for the broad range of phenotypic variation observed among avocado cultivars.

The avocado fruit includes an array of antioxidants (e.g., Ding et al., 2007; Kim et al., 1998, 2000) with manifold beneficial properties, including cholesterol reduction (LopezLedesma et al., 1996) and anticarcinogenicity (D’Ambrosio, 2007; Ding et al., 2009). Dissecting the genetic and environmental factors that control the level of individual nutrients in avocado will provide important information to avocado breeders, growers, and consumers for the selection of nutritionally enriched cultivars. Conventional breeding approaches in avocado involve considerable time and resources, mainly as a result of the avocado's long generation time and extended land requirements. Our goal is to estimate the genetic determination of nutritive traits in avocado as a prelude to the implementation of a program of marker-assisted selection (MAS). In this article we present data on the heritability of

Received for publication 17 Jan. 2013. Accepted for publication 3 Apr. 2013. Supported in part by the California Avocado Commission and by a University of California Discovery Grant.

${ }^{1}$ Current Address: Departamento de Biotecnología Agrícola, CIIDIR-IPN Unidad Sinaloa, 81000 Mexico.

${ }^{2}$ Current Address: Department of Botany \& Plant Sciences, University of California, Riverside, CA 92521.

${ }^{3}$ Corresponding author. E-mail: mclegg@uci.edu. three compounds that are known to confer a health benefit (carotenoids, $\beta$-sitosterol, and vitamin $\mathrm{E}$ ).

Avocados are a significant source of dietary phytosterols, in particular $\beta$-sitosterol, that has been shown to decrease cholesterol absorption in the intestine, thus lowering blood cholesterol levels (Moghadasian and Frohlich, 1999). On average, avocados contain $\approx 760 \mu \mathrm{g} \beta$-sitosterol per gram of fruit or $\approx 114 \mathrm{mg}$ per average avocado (Duester, 2001). Clearly, selection for increased $\beta$-sitosterol content is appealing, but little is known about genetic determination of $\beta$-sitosterol content among avocado genotypes. In a study of rapeseed (Brassica napus), heritability for $\beta$-sitosterol was high: $0.90,0.82$, and 0.85 in three populations grown in three different environments (Amar et al., 2007), making $\beta$-sitosterol a good candidate for selection in rapeseed.

Total carotenoids in avocado are mainly composed of $\beta$-carotene, $\alpha$-carotene, $\beta$-cryptoxanthin, lutein, and zeaxanthin with lutein being the largest component (Lu et al., 2009). The carotenoids in general are antioxidants and are also considered important in combating cancer, eye disease, and other health conditions (Johnson, 2002). Heritability of carotenoids in lettuce (Lactuca sativa) has been estimated to be 0.50 (Gupta et al., 2008), and a study in maize (Zea mays) reported heritability values ranging from 0.49 to 0.87 (Wong et al., 2004). Studies on carrot (Daucus carota) and sorghum (Sorghum bicolor) carotenoids showed higher heritability at $\approx 0.90$ (Fernandez et al., 2008; Santos and Simon, 2002, 2006). Carotenoid-fortified crops have been developed for other species (Römer and Fraser, 2005; Römer et al., 2000).

Vitamin $\mathrm{E}$ is an important antioxidant that functions by binding free radical intermediates. It acts as an inhibitor of platelet aggregation and protects lipids by preventing the oxidation of polyunsaturated fatty acids (Traber and Stevens, 2011). In this study we are measuring $\alpha$-tocopherol, the most biologically active form of vitamin E. The U.S. Department of Agriculture (USDA), Agricultural Research Service reports vitamin E content for a Florida-grown 'Hass' avocado to be 
$\approx 19.7 \mu \mathrm{g} \cdot \mathrm{g}^{-1}$. A study of tocopherol content in sunflower (Helianthus annuus) seeds reported a heritability ranging from 0.67 to 0.78 (Del Moral et al., 2012), making vitamin E a good candidate for selection in that species.

Molecular tools have the potential of improving current avocado breeding efforts (Tester and Langridge, 2010). Selection on molecular markers such as simple sequence repeats (SSRs) or single nucleotide polymorphisms (SNPs) associated with traits of economic value promise to increase breeding efficiency for beneficial traits, especially in long-lived tree crops like avocado. SSR- and SNP-based MAS offers the potential to combine target traits in the same genotype more precisely and with shorter selection cycles than conventional mass selection procedures. We have begun to identify SSR and SNP markers in genes from the carotenoid, $\beta$-sitosterol, and vitamin $\mathrm{E}$ pathways to search for markers that are predictive of high concentrations of these compounds in avocado fruits.

In this article, we examine phenotypic variation for carotenoids, $\beta$-sitosterol, and vitamin $\mathrm{E}$ in a breeding population of avocado, and we determine the broad-sense heritability of these traits in an experimental design based on estimating trait variances within and between clonal genotypes to determine if nutrient concentration will respond efficiently to artificial selection. This design does not permit the estimation of narrow sense heritability, which is important for mass selection, but MAS schemes allow the exploitation of non-additive sources of variation. To measure individual levels of these traits, we developed simple assays for nutrient content that can be applied to hundreds of fruit easily and cheaply. This information will be useful in understanding the relative role of environmental vs. genetic factors in the determination of nutritive trait variation and will assist in providing a basis for selection for nutritive content in avocado fruit.

\section{Materials and Methods}

Plant material. Genetic analysis requires a population of known parentage. For this purpose we used a mapping population composed of a cross between the cultivars Gwen and Fuerte (Gwen $\times$ Fuerte). The maternal parent ('Gwen') has a hybrid origin deriving from Guatemalan and Mexican races of avocado $[\approx 90 \%$ Guatemalan (Chen et al., 2009)]. For all progeny considered here, the identity of the paternal parent ('Fuerte') was confirmed by microsatellite markers (Chen et al., 2007). Cultivar Fuerte is a pure Mexican race avocado (Ashworth and Clegg, 2003; Chen et al., 2009). There are numerous phenotypic differences between the parents, including fruit shape and size and general tree growth habit. Chen et al. (2007) determined heritabilities of growth rate, fruit abundance, and flower abundance for this population.

To construct the breeding population, four clonal replicates of each of 54 F1 progeny of the 'Gwen' $\times$ 'Fuerte' cross were grafted onto a 'Duke 7' rootstock. Two clonal replicates were planted at University of California South Coast Research and Extension Center (SCREC), Irvine, CA. The other two replicates were planted at University of California, Riverside Agricultural Operations, Riverside, CA. The trees were planted between 2001 and 2003 as part of a larger experimental population described in Chen et al. (2007). For the present study, fruit was harvested in 2009 and again in 2010 from trees that are progeny of 'Gwen' $\times$ 'Fuerte'. A total of 274 samples (139 from 2009 and 135 from 2010) were assayed for nutritional traits. In several cases, fruit was not available from all four clonal replicates because either a tree had died or did not produce sufficient fruit for the analysis. We also sampled parental cultivars Gwen and Fuerte grown at SCREC as well as a store-bought fruit of the popular cultivar Hass.

DRY WEIGHT ANALYSIS. Dry weight is a measure of oil content and an indicator of fruit maturity. Commercially, avocados are harvested when dry weight exceeds $20 \%$. Our goal was to select and process avocado fruit in a manner that replicates the stage and condition of fruit that a consumer would likely consume. Dry weight was determined by a method developed by Lee et al. (1983). First a plug of avocado tissue is taken using a cork borer. The peel is removed and the plug weighed. The plug is then heated in a microwave oven on a medium-low setting for $35 \mathrm{~min}$. The plug is again weighed. This process is repeated until all the water has been driven from the sample and there is no further reduction in weight.

Fruit PREPARATION. Five fruit with a dry weight greater than $20 \%$ were selected from each tree and allowed to soften in the laboratory. The flesh was then separated from the peel and seed. The flesh from all five fruit was combined and homogenized with a mortar and pestle. Aliquots of the combined fruit were then frozen at $-80^{\circ} \mathrm{C}$ for later chemical analysis.

NutRITIVE ASSAYs. The following procedure for the extraction of the non-water-soluble nutrients was adapted for avocado from methods previously published for other species (Jeong and Lachance, 2001; Mäeorg et al., 2007; Ryan et al., 2007). Avocado mesocarp tissue $(0.5 \mathrm{~g})$ was homogenized in a FastPrep24 instrument (MP Biomedicals, Santa Ana, CA) using lysing Matrix D (MP Biomedicals) with $1 \mathrm{~mL}$ of absolute ethanol with $6 \%$ pyrogallol and $5 \mathrm{~mL} \mathrm{HCl}$. The homogenate was incubated for $15 \mathrm{~min}$ at $70{ }^{\circ} \mathrm{C}$ and then allowed to cool to room temperature followed by addition of $20 \mu \mathrm{L} 0.4 \% \mathrm{NaCl}$ and extraction of the homogenate with $4 \mathrm{~mL}$ hexane/petroleum ether (1:1). The upper organic phase was removed and the aqueous layer re-extracted with $2 \mathrm{~mL}$ hexane/petroleum ether (1:1). The organic phases were combined and $50 \mu \mathrm{L} 6 \%$ pyrogallol in absolute ethanol was added. A $100-\mu \mathrm{L}$ aliquot of the aqueous phase was removed and a spectrophotometric reading at $456 \mathrm{~nm}$ was used for determining total carotenoid concentration relative to a standard curve using $\beta$-carotene (C4582; Sigma-Aldrich, St. Louis, MO) based on the method of Luterotti et al. (2006). This assay for total carotenoid

Table 1. Analysis of variance for $\alpha$-tocopherol (vitamin E), $\beta$-sitosterol, and carotenoids in avocado fruit measured in 2009 and 2010 in the 'Gwen' $\times$ 'Fuerte' breeding population. ${ }^{\mathrm{x}}$

\begin{tabular}{lccc}
\hline & $\alpha$-tocopherol & $\beta$-sitosterol & Carotenoids \\
\hline Distribution & \\
Variance source & Non-normal $^{\mathrm{y}}$ & Non-normal & Normal \\
Genotype (G) & $* * * / * * * \mathrm{x}$ & $* * * / * * *$ & $* * * / \mathrm{ND}$ \\
Year (Y) & $* / *$ & $* * * / * *$ & $* * * / \mathrm{ND}$ \\
Location (L) & $\mathrm{NS} / \mathrm{NS}$ & $\mathrm{NS} / \mathrm{NS}$ & $* * * / \mathrm{ND}$ \\
$\mathrm{G} \times \mathrm{L}$ & $\mathrm{NS} / \mathrm{NS}$ & $* * / *$ & $* / \mathrm{ND}$ \\
$\mathrm{G} \times \mathrm{Y}$ & $\mathrm{NS} / \mathrm{NS}$ & $* * * / * * *$ & $\mathrm{NS} / \mathrm{ND}$ \\
\hline
\end{tabular}

${ }^{\mathrm{z}}$ Normality tested using Shapiro-Wilk test of $\log 10$-transformed data. ${ }^{y}$ Normally distributed based on Box-Cox-transformed data.

${ }^{x}$ Before and after slash: based on $\log 10$-transformed or Box-Coxtransformed data, respectively; $\mathrm{NS}, *, * *, * * *$ nonsignificant or significant at $P \leq 0.01,0.001,0.0001$, respectively; $\mathrm{ND}=$ not determined. 


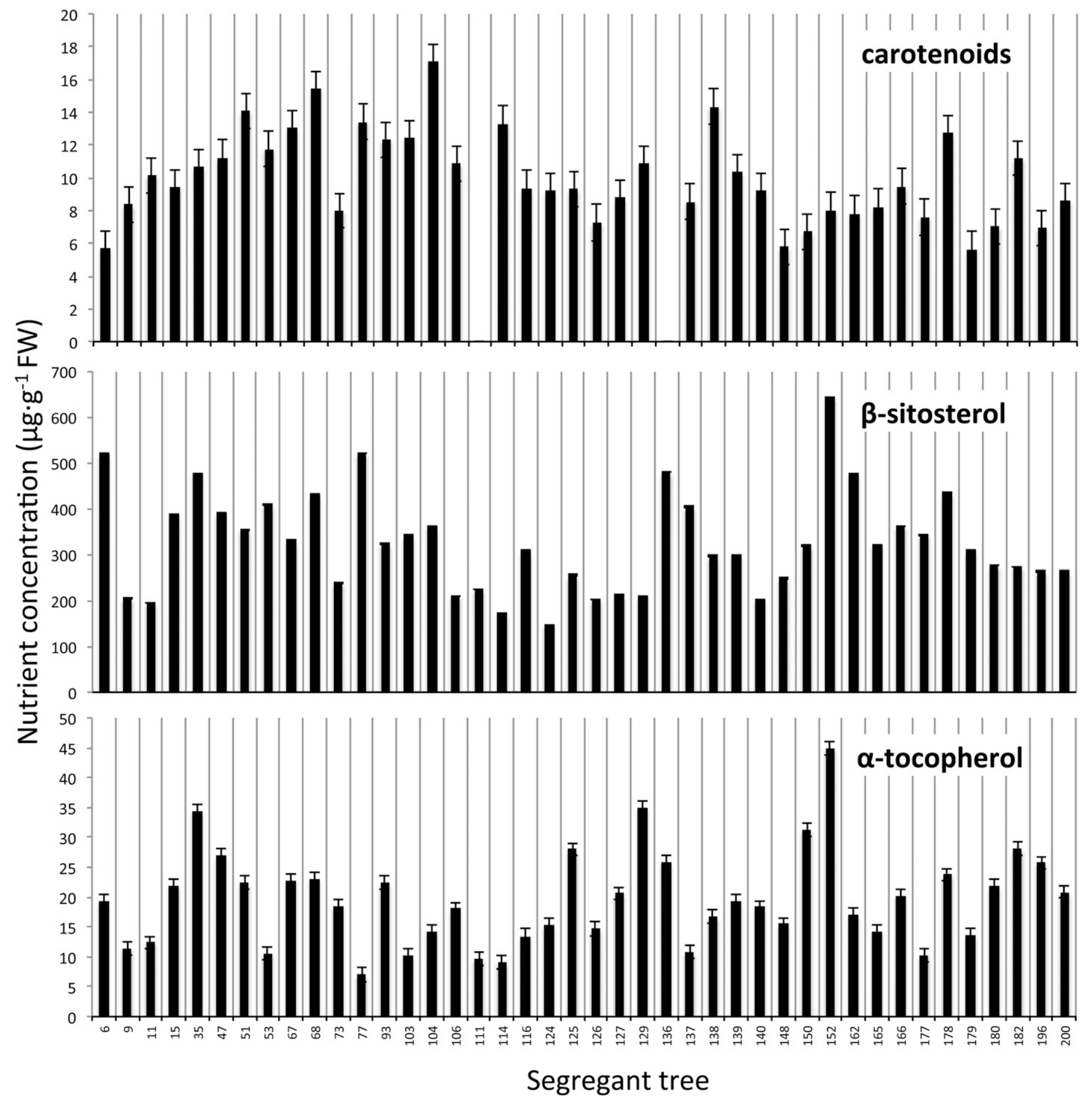

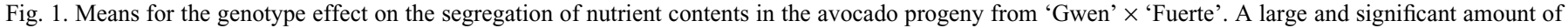
variation was found among segregant trees for carotenoids, $\beta$-sitosterol and $\alpha$-tocopherol, indicating a substantial genetic component of the variation. Error bars represent \pm SE. Missing columns in some nutrient plots means that there was not enough data.

concentration represents the sum of neoxanthin, violaxanthin, neochrome, lutein-5,6-epoxide, chrysanthemaxanthin, lutein, zeaxanthin, $\beta$-cryptoxanthin, $\alpha$-carotene, and $\beta$-carotene components. It differs slightly from the method used by the USDA that represents the sum of $\beta$-carotene, $\alpha$-carotene, $\beta$-cryptoxanthin, lycopene, lutein, and zeaxanthin (USDA, 2012).

The rest of the organic phase was evaporated to an oily residue. The oil was rinsed four times with $0.2 \mathrm{~mL}$ methanol.
The methanol washes were then combined and evaporated leaving an oil residue. The oil was saponified by adding $0.3 \mathrm{~mL} 1 \%$ pyrogallol in absolute ethanol and $200 \mu \mathrm{L} 10 \mathrm{M}$ $\mathrm{KOH}$. This mixture was allowed to incubate at room temperature for $30 \mathrm{~min}$ and then $0.3 \mathrm{~mL} \mathrm{H}_{2} \mathrm{O}$ and $20 \mu \mathrm{L}$ of $0.4 \% \mathrm{NaCl}$ were added and then extracted two times with $0.6 \mathrm{~mL}$ petroleum ether. The ether phase was then combined and washed three times with $0.5 \mathrm{~mL} \mathrm{H}_{2} \mathrm{O}$. The ether was then evaporated and the residue reconstituted in $10 \mu \mathrm{L}$ methanol. 
For vitamin E quantitation, $6 \mu \mathrm{L}$ of the reconstituted residue was applied to a Whatman LHPKDF 60A $200 \mu \mathrm{M}$ TLC plate (GE Healthcare Life Sciences, Piscataway, NJ). The plate was developed in hexane:ethyl acetate (9:1). Varying amounts of $\alpha$-tocopherol (T3251; Sigma-Aldrich) were also applied to the plate to generate a standard curve for vitamin $\mathrm{E}$. For $\beta$-sitosterol, $3 \mu \mathrm{L}$ of a $1: 25$ dilution of the reconstituted residue was applied to a Whatman LHPKDF $60 \mathrm{~A} 200 \mu \mathrm{M}$ TLC plate, which was then developed with hexane:acetone (40:10) as the solvent. $\beta$-sitosterol (S1270; Sigma-Aldrich) was used for the standard. The plates were dried and dipped in phosphomolybdic acid (02553; SigmaAldrich) to visualize the bands. The bands were quantified on an AlphaImager HP System (ProteinSimple, Santa Clara, CA).

ESTIMATION OF HERITABILITY AND GENETIC CORRELATIONS. Phenotypic data analyses were performed using SAS statistical software package (Version 9.2; SAS Institute, Cary, NC). Proc GLM (using Type III sum of squares and a significance level set to $5 \%$ ) was used for adjusting a linear model on natural, $\log 10$-, and Box-Cox-transformed nutrient data to assess the effect of genotype, harvest year, location, genotype $\times$ location interaction, and genotype $\times$ year interaction on nutrient contents. Means, range of means, and SES were calculated for combined years on the data using the LSMEANS statement for the genotype factor. The variance components and estimates of broad-sense heritability $\left(H^{2}\right)$ were calculated as the ratio between the total genetic variance and the total variance using the estimates from the SAS PROC VARCOMP program. Pearson's product moment correlation coefficient among the nutrient contents was calculated from the genotype means for all three pairwise comparisons using the PROC CORR procedure.

\section{Results}

Table 1 shows the analysis of variance for $\beta$-sitosterol, carotenoids, and vitamin E. The analysis shows that the genotype factor is highly significant for all the nutrient traits, whereas the harvest year, location, and its interactions are less significant in the model. Figure 1 displays the mean trait values across genotypes for each of the three nutritive traits. The data clearly reveal substantial differences between genotypes for all three traits, indicating a substantial genetic component to the variation. Figure 2 shows the means for the location and harvest year effects. There was a significant difference between harvest year for sitosterol content and for both location and year for carotenoid concentration. For vitamin E, on the other hand, no significant differences were detected. We now consider each trait in greater detail.

$\boldsymbol{\beta}$-sitosterol. Average $\beta$-sitosterol levels in 42 out of the 54 'Gwen' $\times$ 'Fuerte' progeny genotypes that presented enough fruit samples ranged from 146 to $642 \mu \mathrm{g} \cdot \mathrm{g}^{-1}$. We also determined $\beta$-sitosterol levels in the fruit of parental cultivars Gwen and Fuerte that were growing at SCREC. The fruit of the cultivar Gwen contained $469 \mu \mathrm{g} \cdot \mathrm{g}^{-1}$ of $\beta$-sitosterol, whereas the cultivar Fuerte contained $672 \mu \mathrm{g} \cdot \mathrm{g}^{-1}$. In the 'Gwen' $\times$ 'Fuerte' study population, six progeny genotypes had levels higher than the maternal parent.

The calculated $H^{2}$ for $\beta$-sitosterol was $\approx 0.79$ in the 2009 harvest and $\approx 0.55$ in the 2010 harvest (depending on the transformation used for the data) (Table 2). Combining data
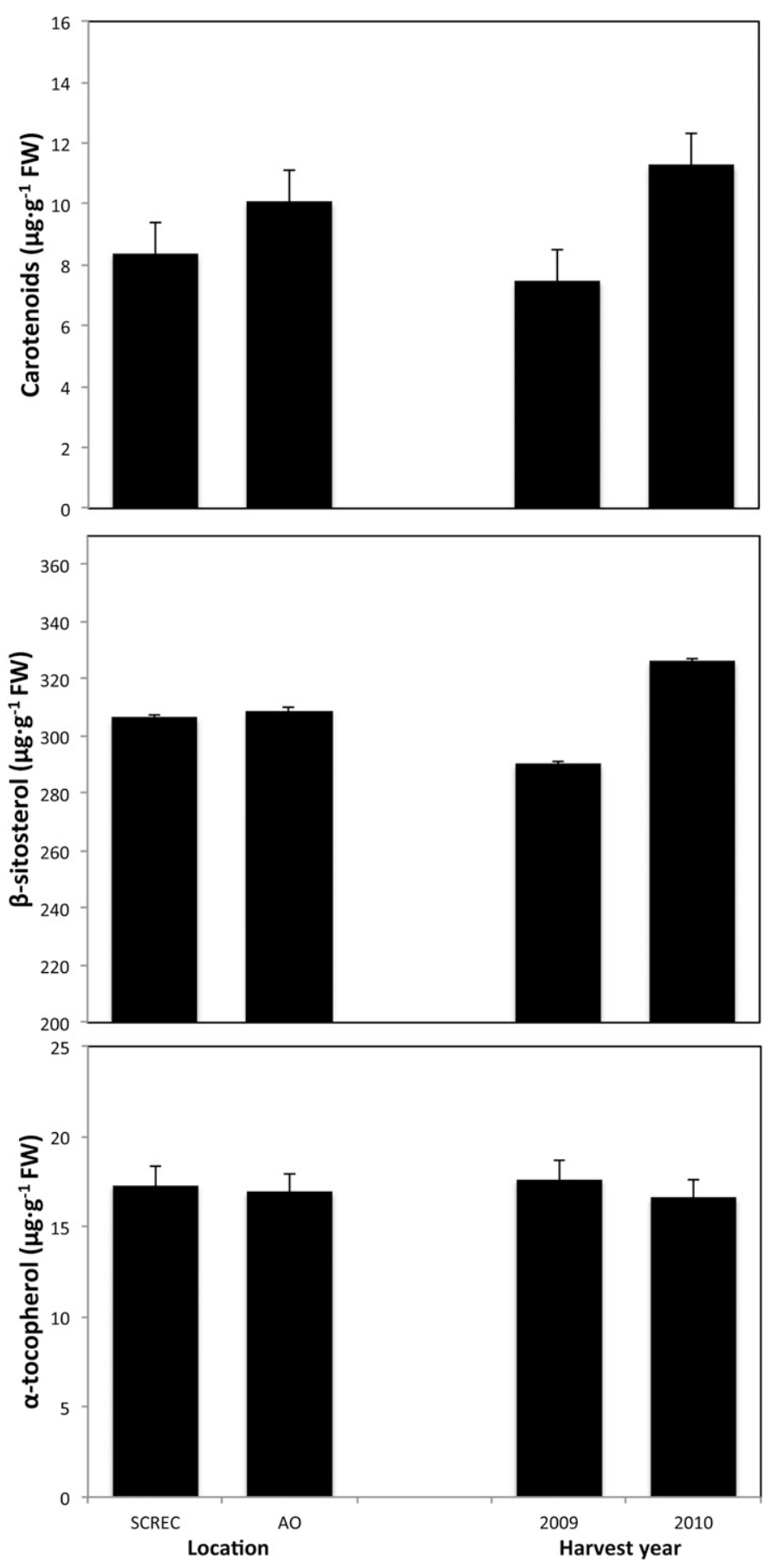

Fig. 2. Means of nutrient contents for location (left) and year (right) effects in avocado 'Gwen' $\times$ 'Fuerte' segregant trees. Significant differences were found for the year effect when analyzing carotenoids and $\beta$-sitosterol. For $\alpha$-tocopherol, no differences were detected for either effect. SCREC $=$ University of California South Coast Research and Extension Center, Irvine, $\mathrm{CA} ; \mathrm{AO}=$ University of California Riverside Agricultural Operations, Riverside, CA; error bars represent \pm SE.

from both years, $H^{2}$ was 0.65 . These values indicate that the genetic component dominates the environmental component of variance for $\beta$-sitosterol levels, making $\beta$-sitosterol a good candidate for selection.

Total Carotenoids. The concentration of total carotenoids in the 40 'Gwen' $\times$ 'Fuerte' progeny that presented fruit 
Table 2. Broad-sense heritability of the analyzed nutrients in avocado. ${ }^{\mathrm{z}}$

\begin{tabular}{lcccccc}
\hline & \multicolumn{3}{c}{$\alpha$-tocopherol } & \multicolumn{2}{c}{$\beta$-sitosterol } & \multicolumn{2}{c}{ Carotenoids } \\
\hline & $\log 10^{\mathrm{y}}$ & Box-Cox & $\log 10$ & Box-Cox & $\log 10$ & Box-Cox $^{\mathrm{y}}$ \\
Single-year (2009) & 0.64 & 0.64 & 0.79 & 0.79 & 0.50 & ND $^{\mathrm{x}}$ \\
Single-year (2010) & 0.77 & 0.78 & 0.54 & 0.57 & 0.59 & ND \\
Combined $(2009+2010)$ & 0.76 & 0.76 & 0.61 & 0.65 & 0.47 & ND \\
\hline
\end{tabular}

${ }^{\mathrm{z}}$ Single-year and combined data are shown.

${ }^{\mathrm{y}} \log 10$ and Box-Cox $=$ based on $\log 10$-transformed or Box-Cox-transformed data.

${ }^{\mathrm{x}} \mathrm{ND}=$ not determined.

Table 3. Pearson product moment correlations among mean values of $\alpha$-tocopherol, $\beta$-sitosterol, and carotenoid contents of the avocado progeny of 'Gwen' $\times$ 'Fuerte'.

\begin{tabular}{lccc}
\hline & $\alpha$-tocopherol & $\beta$-sitosterol & Carotenoids \\
\hline$\alpha$-tocopherol & 1 & $0.32^{*}$ & -0.07 \\
$\beta$-sitosterol & & 1 & 0.11 \\
Carotenoids & & & 1 \\
\hline
\end{tabular}

*Significant at $P \leq 0.05$.

samples ranged from 5.63 to $17.09 \mu \mathrm{g} \cdot \mathrm{g}^{-1}$, indicating appreciable variation between progeny genotypes. Figure 1 shows the range of genotypic means. We analyzed the parental cultivars Gwen and Fuerte grown at SCREC and determined total carotenoid concentrations of 8.37 and $9.8 \mu \mathrm{g} \cdot \mathrm{g}^{-1}$, respectively. Several of the genotypes had higher values for total carotenoids than either of the parental types.

We determined the broad-sense heritability of total carotenoid concentration in the progeny of the 'Gwen' $\times$ 'Fuerte' cross to be 0.47 across the 2 years (Table 2). When the carotenoid data set is partitioned by year, the broad-sense heritability is higher $(0.50$ in $2009,0.59$ in 2010), because the GLM model used within single years reports a larger proportion of the total variance than across years. Location and year also had a significant effect on carotenoid concentration $(P<0.0001)$. Genotype $\times$ year interaction did not have a significant effect $(P=0.19)$, whereas genotype $\times$ location interaction was significant $(P<0.003$; Table 1).

Vitamin E. The concentration of vitamin $\mathrm{E}$ in the analyzed progeny ranged from a low of 6.98 to a high of $44.94 \mu \mathrm{g} \cdot \mathrm{g}^{-1}$. Figure 1 depicts the range of vitamin $\mathrm{E}$ concentration among progeny for the combined harvests. Concentrations of vitamin E in cultivars Gwen and Fuerte grown at SCREC were 19.5 and $19.0 \mu \mathrm{g} \cdot \mathrm{g}^{-1}$, respectively. A few progeny had considerably higher values than the parental types. Broad-sense heritability for vitamin $\mathrm{E}$ in the 'Gwen' $\times$ 'Fuerte' progeny was 0.64 for 2009 and 0.77 for 2010 (Table 2). Heritability for the combined years was 0.76 .

GeNETIC CORRELATIONS. The correlation among genotypes (Table 3) for each of the three pairwise trait combinations was calculated from the mean values for each genotype. The correlations are low and only significant in one case in which $R^{2}$ is $32 \%$. The absence of a genetic correlation is not surprising given that each compound is the product of a separate biochemical pathway.

\section{Discussion}

Four key results emerge from this investigation: 1) there is substantial variation among progeny genotypes for all three phenotypic traits; 2) the heritabilities for the three nutrient traits are moderate to high; 3 ) the genetic correlations among traits are low; and 4) the location and year variances are small relative to between-genotype variances. We briefly consider each of these four points in turn.

VARIATION AMONG PROGENY GENOTYPES. Figure 1 displays the mean trait values for each genotype and shows that the range of mean variation is 4 -fold or greater. This establishes that there is substantial genetic variation segregating for each trait among progeny of the 'Gwen' $\times$ 'Fuerte' cross. An interesting aspect of the progeny variation is that some genotypes exceed the two parental nutrient trait values. This phenomenon, sometimes called transgressive segregation, has also been observed in other studies of hybrid populations (Brown et al., 2006). Possible causes of transgressive segregation include overdominance caused by heterozygosity at specific loci, epistatic effects between alleles, and recombination of additive alleles. The current experiment does not permit us to discriminate between these various causes, but it does tell us that simple mass selection will not result in an optimal population. More sophisticated methods of selection will need to be used for this end (Falconer and MacKay, 1996).

Moderate to High heritabiLities. The finding of moderate to high heritabilities is consistent with studies in other plants and is not surprising because nutritive traits are the end products of individual biochemical pathways. It is likely that the environmental variance could be further reduced by finer control of some of the experimental procedures. For example, many non-genetic factors can affect the level of a nutritive trait in the avocado fruit. An important consideration for a breeding program is how to harvest and treat the fruit in a consistent manner before analysis to reduce this source of experimental error. We used fruit that had a dry weight of $20 \%$ or greater, which reflects the oil content of the fruit. That value can climb to over $30 \%$. We combined five fruit per tree to try to average over individual fruit variation, but a larger pool size could be chosen. Also, the softness of the fruit at the time the tissue is prepared for analysis can have an effect on the level of nutrients. We tried to use fruit that represented what a consumer would purchase (oil content reflecting maturity and softness for eating) so as to analyze fruit with a typical nutrient concentration at the time of consumption. Some between-year variation likely arose because the 2010 collection of fruit took place a couple of months later than the 2009 collection. The levels of $\beta$-sitosterol and carotenoids in the 2010 harvest are $\approx 10 \%$ higher overall than the 2009 harvest and may be higher because of the later harvest date. This additional source of variance partially explains the lower heritability in estimates when the data are pooled over years. Although high, broadsense heritability for $\beta$-sitosterol $(0.65)$ is somewhat lower than values found for rapeseed [0.82 to 0.90 (Amar et al., 2007)].

Low GENETIC CORRELATIONS. As is apparent in Figure 1, there is substantial variation among genotypes for all nutrient traits assayed. Consistent with the low genetic correlations among traits, few if any of the cultivars have high levels of all three nutrients. So each trait will need to be selected independently.

Small Variances Resulting from location. An unexpected result was the nonsignificant location effect for vitamin $\mathrm{E}$ and $\beta$-sitosterol (Table 1; Fig. 2). Subdividing the carotenoid 
data set by growing location reveals that mean total carotenoid concentration was higher in Riverside than in Irvine (10.06 $\mu \mathrm{g} \cdot \mathrm{g}^{-1}$ vs. $8.37 \mu \mathrm{g} \cdot \mathrm{g}^{-1}$, respectively) across 2009 and 2010 . This may be related to the difference in climate and soil quality between Riverside and Irvine. In Riverside, the climate is more extreme than in Irvine: humidity is lower, summers are hotter, winters are colder, and the soil is sandier. The present results suggest that avocados grown in the more extreme Riverside environment do not suffer a loss in nutrient content, and in fact, this environment may be favorable from the standpoint of carotenoid content.

Many location-dependent environmental factors such as water stress, temperature, and light can play a key role in inducing production of various nutrients. Moreover, an important confounding effect in the between-location comparison is that the Riverside population was planted in $2003, \approx 18$ months after the planting of the SCREC population, so on average the Riverside trees were younger (see Chen et al., 2007). Despite these location differences, the performance of the progeny genotypes over location is reasonably stable. This implies that genotypes selected for high nutrient traits will exhibit a reasonably predictable performance over the range of environments typical for avocado culture.

The moderate to high heritabilities of the nutrient traits coupled with high levels of genotypic variation and reasonably stable performance over locations and years indicate that nutrient improvement should be achievable in avocado. The traits studied here, $\beta$-sitosterol, carotenoids, and vitamin $\mathrm{E}$, are desirable value-added traits with proven health benefits. As such, these traits are good candidates for a program of MAS selection in avocado. At this time, SNP markers are being identified from candidate genes related to the respective nutrient biosynthetic pathways. SNP markers could then be associated with high concentration phenotypes for further selection. The implementation of such a program has the potential to accelerate avocado breeding progress substantially.

\section{Literature Cited}

Amar, S., H.C. Becker, and C. Möllers. 2007. Genetic variation and genotype $\times$ environment interactions for phytosterol content in rapeseed (Brassica napus L.). Proc. 12th Intl. Rapeseed Congr. $1: 340-342$.

Arumuganathan, K. and A.D. Earle. 1991. Nuclear DNA concentration of some important plant species. Plant Mol. Biol. Rpt. 9:208219.

Ashworth, V.E.T.M., H. Chen, and M.T. Clegg. 2011. Persea, p. 173189. In: Kole, C. (ed.). Wild crop relatives: Genomic and breeding resources. Tropical and subtropical fruits. Springer-Verlag, Berlin, Germany.

Ashworth, V.E.T.M. and M.T. Clegg. 2003. Microsatellite markers in avocado (Persea americana Mill.): Genealogical relationships among cultivated avocado genotypes. J. Hered. 94:407-415.

Bergh, B. 1992. The avocado and human nutrition. I. Some human health aspects of the avocado. Proc. 2nd World Avocado Congr. $1: 25-35$.

Brown, C.R., T.S. Kim, Z. Ganga, K. Haynes, D.D. Jong, M. Jahn, I. Paran, and W.D. Jong. 2006. Segregation of total carotenoid in high level potato germplasm and its relationship to beta-carotene hydroxylase polymorphism. Amer. J. Potato Res. 83:365-372.

Chen, H., V.E.T.M. Ashworth, S. Xu, and M.T. Clegg. 2007. Quantitative genetic analysis of growth rate in avocado. J. Amer. Soc. Hort. Sci. 132:691-696.
Chen, H., P.L. Morrell, V.E.T.M. Ashworth, M. De La Cruz, and M.T. Clegg. 2009. Tracing the geographic origins of major avocado cultivars. J. Hered. 100:56-65.

Chen, H., P.L. Morrell, M. De la Cruz, and M.T. Clegg. 2008. Nucleotide diversity and linkage disequilibrium in wild avocado (Persea americana Mill.). J. Hered. 99:382-389.

D'Ambrosio, S.M. 2007. Phytonutrients: A more natural approach toward cancer prevention. Semin. Cancer Biol. 17:345-346.

Del Moral, L., J.M. Fernández-Martínez, L. Velasco, and B. PérezVich. 2012. Quantitative trait loci for seed tocopherol content in sunflower. Crop Sci. 52:786-794.

Ding, H., Y.W. Chin, A.D. Kinghorn, and S.M. D'Ambrosio. 2007. Chemopreventive characteristics of avocado fruit. Semin. Cancer Biol. 17:386-394.

Ding, H., C. Han, D. Guo, Y.W. Chin, Y. Ding, A.D. Kinghorn, and S.M. D'Ambrosio. 2009. Selective induction of apoptosis of human oral cancer cell lines by avocado extracts via a ROS-mediated mechanism. Nutr. Cancer 61:348-356.

Duester, K.C. 2001. Avocado fruit is a rich source of beta-sitosterol. J. Amer. Diet Assn. 101:404-405.

Falconer, D.S. and T.F.C. MacKay. 1996. Introduction to quantitative genetics. 4th Ed. Pearson Education, Harlow, UK.

Fernandez, M.G.S., M.T. Hamblin, L. Li, W.L. Rooney, M.R. Tuinstra, and S. Kresovich. 2008. Quantitative trait loci analysis of endosperm color and carotenoid concentration in sorghum grain. Crop Sci. 48:1732-1743.

Galindo-Tovar, M.E., N. Ogata-Aguilar, and A.M. Arzate-Fernández. 2008. Some aspects of avocado (Persea americana Mill.) diversity and domestication in Mesoamerica. Genet. Crop Evol. 55:441450.

Gupta, A.J., T. Dolma, M.A. Chattoo, and S. Yasmin. 2008. Estimation of genetic variability and heritability in lettuce (Lactuca sativa L.). Indian J. Plant Genet. Resources 21:138-140.

Johnson, E.J. 2002. The role of carotenoids in human health. Nutr. Clin. Care 5:56-65.

Jeong, W.S. and P.A. Lachance. 2001. Phytosterols and fatty acids in fig (Ficus carica, var. Mission) fruit and tree components. J. Food Sci. 66:278-281.

Kim, O.K., A. Murakami, Y. Nakamura, and H. Ohigashi. 1998. Screening of edible Japanese plants for nitric oxide generation inhibitory activities in RAW 264.7 cells. Cancer Lett. 125:199-207.

Kim, O.K., A. Murakami, Y. Nakamura, N. Takeda, H. Yoshizumi, and H. Ohigashi. 2000. Novel nitric oxide and superoxide generation inhibitors, persenone A and B, from avocado fruit. J. Agr. Food Chem. 48:1557-1563.

Lee, S.K., P.M. Young, P.M. Schiffman, and C.W. Coggins. 1983. Maturity studies of avocado fruit based on picking dates and dry weight. J. Amer. Soc. Hort. Sci. 108:390-394.

Lopez-Ledesma, R., A.C. Frati-Munari, B.C. Hernandez-Dominguez, S. Cervantes-Montalvo, M.H. Hernandez-Luna, C. Juarez, and S. Moran-Lira. 1996. Monounsaturated fatty acid (avocado) rich diet for mild hypercholesterolemia. Arch. Med. Res. 27:519-523.

Lu, Q., Y. Zhang, Y. Wang, D. Wang, R. Lee, K. Gao, R. Byrns, and D. Heber. 2009. California Hass avocado: Profiling of carotenoids, tocopherol, fatty acid, and fat concentration during maturation and from different growing areas. J. Agr. Food Chem. 57:1040810413.

Luterotti, S., D. Bicanic, and R. Požgaj. 2006. New simple spectrophotometric assay of total carotenes in margarines. Anal. Chim. Acta 573-574:466-473.

Mäeorg, E., P. Lääniste, J. Jöudu, and U. Mäeorg. 2007. Some important aspects of sterol analysis of vegetable oils. Proc. Estonian Acad. Sci. Chem. 56:59-66.

Moghadasian, M.H. and J.J. Frohlich. 1999. Effects of dietary phytosterols on cholesterol metabolism and atherosclerosis: Clinical and experimental evidence. Amer. J. Med. 107:588-594.

Römer, S. and P.D. Fraser. 2005. Recent advances in carotenoid biosynthesis, regulation and manipulation. Planta 221:305-308. 
Römer, S., P.D. Fraser, J.W. Kiano, C.A. Shipton, N. Misawa, W. Schuch, and P.M. Bramley. 2000. Elevation of the provitamin A concentration of transgenic tomato plants. Nat. Biotechnol. 18:666-669.

Ryan, E., K. Galvin, T.P. O'Connor, A.R. Maguire, and N.M. O’Brien. 2007. Phytosterol, squalene, tocopherol content and fatty acid profile of selected seeds, grains, and legumes. Plant Foods Hum. Nutr. 62:85-91.

Santos, C.A.F. and P.W. Simon. 2002. QTL analyses reveal clustered loci for accumulation of major provitamin A carotenes and lycopene in carrot roots. Mol. Genet. Genomics 268:122-129.

Santos, C.A.F. and P.W. Simon. 2006. Heritabilities and minimum gene number estimates of carrot carotenoids. Euphytica 151:7986.
Smith, C.E., Jr. 1966. Archaeological evidence for selection in avocado. Econ. Bot. 20:169-175.

Tester, M. and P. Langridge. 2010. Breeding technologies to increase crop production in a changing world. Science 327:818-822.

Traber, M.G. and J.F. Stevens. 2011. Vitamins C and E: Beneficial effects from a mechanistic perspective. Free Radic. Biol. Med. 51:1000-1013.

U.S. Department of Agriculture. 2012. USDA national nutrient database for standard reference, release 25 . Nutrient data laboratory home page. 10 Dec. 2012. <http://www.ars.usda.gov/ba/bhnrc/ndl >. Wong, J.C., R.J. Lambert, E.T. Wurtzel, and T.R. Rocheford. 2004. QTL and candidate genes phytoene synthase and $\beta$-carotene desaturase associated with the accumulation of carotenoids in maize. Theor. Appl. Genet. 108:349-359. 